\title{
CHARACTERIZATION OF THE PEPTIDE AND SENSORY NEUROTOXIC EFFECTS OF CAPSAICIN IN THE GUINEA PIG ${ }^{1}$
}

\author{
STEPHEN H. BUCK, ${ }^{*}, 2$ JOHN H. WALSH, $\ddagger, \S$ THOMAS P. DAVIS, ${ }^{*}$ MARVIN R. BROWN, $\|$ \\ HENRY I. YAMAMURA, ${ }^{*}$ AND THOMAS F. BURKS ${ }^{* 3}$
}

${ }^{*}$ Department of Pharmacology, College of Medicine, University of Arizona Health Sciences Center, Tucson, Arizona 85724, $\$$ Department of Medicine, School of Medicine, University of California, Los Angeles, California 90024, \$Center for Ulcer Research and Education, Veterans Administration Center, Los Angeles, California 90037, and || The Peptide Biology Laboratory, The Salk Institute for Biological Studies, La Jolla, California 92037

Received January 24, 1983; Revised April 13, 1983; Accepted April 28, 1983

\begin{abstract}
The effects of capsaicin, the major pungent ingredient of hot peppers, were assessed on sensory neuron neuropeptide levels and on sensory function in the adult guinea pig. Systemic doses of capsaicin as low as $2.5 \mathrm{mg} / \mathrm{kg}$ depleted substance $\mathrm{P}$ (SP) in dorsal roots plus ganglia (DRG) whereas a $10-\mathrm{mg} / \mathrm{kg}$ dose depleted the peptide maximally in DRG and in the dorsal spinal cord. High doses of capsaicin had no consistent effects on levels of cholecystokinin (CCK), vasoactive intestinal polypeptide, or somatostatin, although a transient decrease in CCK levels was observed 4 days after dosing. A single $5-\mathrm{mg} / \mathrm{kg}$ dose of capsaicin rendered animals completely insensitive to chemical irritation of the cornea without affecting sensitivity to noxious heat. Higher doses of capsaicin produced a marked insensitivity to nociceptive and non-nociceptive heat as well as to chemical irritation without affecting other sensory modalities. The SP depletion and sensory deficits produced by a single $50-\mathrm{mg} / \mathrm{kg}$ dose of capsaicin were still evident 10 weeks later. The pattern of selectivity of the sensory deficits produced by capsaicin differed from that produced by morphine which was active against all forms of nociceptive stimuli. The results indicate that in the guinea pig capsaicin is potent at producing a unique, long-lasting syndrome of peripheral sensory deficits that may result from an effect of the agent on SP-containing primary afferent neurons.
\end{abstract}

Capsaicin (8-methyl- $N$-vanillyl-6-nonenamide), the major pungent ingredient of hot peppers of the plant genus Capsicum, has been known for many years to alter certain sensory functions in laboratory animals. Topical application produced a localized inflammatory reaction apparently accompanied by painful irritation after which there was an insensitivity of the area to chemical irritants. Systemic administration of capsaicin produced a similar insensitivity that lasted for weeks to months in the treated animals. This effect apparently resulted from a selective effect of the compound on primary afferent

\footnotetext{
${ }^{1}$ Supported by United States Public Health Service (USPHS) Grants DA02163, NS15420, MH30626, and AM17328. H. I. Y. is a recipient of a Research Scientist Development Award, Type II (MH-00095) from the National Institute of Mental Health. S. H. B. was a USPHS Predoctoral Fellow during the tenure of this research. Portions of this work were presented at the 1981 Western Pharmacology Society Meeting and were published in the Proceedings.

${ }^{2}$ Present address: Section on Biochemical Pharmacology, Hypertension-Endocrine Branch, NHLBI, NIH, Bethesda, Maryland 20205.

${ }^{3}$ To whom correspondence should be addressed.
}

neurons mediating certain kinds of peripheral stimuli. In the rat, capsaicin markedly reduced the sensitivity to nociceptive chemicals without affecting responsiveness to touch or mechanical or thermal pain (Jancso, 1968). This action on sensory neurons in the adult rat was reported to be accompanied by alterations in mitochondrial structure and depletion of cytoplasmic vesicles in peripheral processes of sensory neurons and in type B dorsal root ganglion cells. The morphological changes were long-lasting, but no evidence of actual neuronal degeneration was seen (Joo et al., 1969; Szolcsanyi et al., 1975). Systemic treatment of neonatal rats with capsaicin, however, produced a permanent insensitivity to chemical irritation that was accompanied by degeneration of small sensory neurons (Jancso et al., 1977).

Two early reports from eastern Europe suggested that capsaicin alters the biochemistry of some sensory neurons. Gasparovic and co-workers (1964) observed that the amount of bioassayable substance $P$ (SP) was reduced in the spinal cord but not in the brain of rats treated with capsaicin. SP is an undecapeptide thought to be a neurotransmitter or neuromodulator in some 
sensory neurons giving rise to small unmyelinated fibers (type C) (see Leeman and Gamse, 1981). In addition to SP, capsaicin treatment of rats also depleted fluorideresistant acid phosphatase activity, thought to be associated with central terminals of primary afferent neurons mediating certain nociceptive stimuli, from the dorsal horn of the spinal cord (Jancso and Knyihar, 1975). In 1978, Jessell and colleagues determined that radioimmunoassayable SP levels were reduced by $50 \%$ in the dorsal horn after systemic capsaicin treatment of adult rats. The depletion was also observed by fluorescent visualization of SP immunoreactivity and apparently did not result from a general neurotoxic action of capsaicin or from degeneration of primary afferent central processes since spinal glutamic acid decarboxylase activity and opioid-binding sites were not affected (Jessell et al., 1978).

'Iwo other laboratories subsequently reported that treatment of neonatal rats with capsaicin produced a permanent reduction in sensory neuron SP levels that was accompanied by neuronal degeneration, a reduction in the number of opioid-binding sites, and a life-long impairment of the neurogenic plasma extravasation response in the treated animals (Gamse et al., 1979, 1980; Nagy et al., 1980). Numerous groups have confirmed the SP depletion by capsaicin in sensory neurons and tissues innervated by these neurons (for reviews see Virus and Gebhart, 1979; Buck et al., 1982b; Nagy, 1982; Buck and Burks, 1983). The depletion occurs in rats (Jessell et al., 1978; Nagy et al., 1980; Gamse et al., 1979, 1980, 1981b; Hayes and Tyers, 1980), mice (Gamse, 1982), and guinea pigs (Buck et al., 1981b; Gamse et al., 1981c; Furness et al., 1982). The loss of SP is remarkably selective for sensory neurons since it does not occur in intrinsic neurons of the brain or of the gastrointestinal tract (Nagy et al., 1980; Gamse et al., 1980; Holzer et al., 1980; Buck et al., 1981a; Furness et al., 1982). It is clear that treatment of neonatal animals with capsaicin results in an irreversible loss of unmyelinated sensory neurons (Jancso and Kiraly, 1980; Scadding, 1980), and recent microscopic studies have suggested that capsaicin produces some changes resembling neuronal degeneration in adult animals (Hoyes and Barber, 1981; Papka et al., 1982).

Although treatment of neonatal rats with capsaicin results in complete insensitivity to chemical irritants (Jancso et al., 1977), the treated animals exhibit only a slight decrease in their sensitivity to nociceptive heat (Holzer et al., 1979; Nagy et al., 1980; Gamse, 1982) that some laboratories have had difficulty in reproducing (Cervero and McRitchie, 1981; Hayes et al., 1981; Buck et al., 1982a). Adult rats treated systemically with capsaicin clearly do not have a reduction in their sensitivity to noxious heat at times when primary afferent SP levels are markedly depleted, even though the animals are insensitive to chemical irritants and show reduced responsiveness to nociceptive pressure (Obal et al., 1979; Hayes and Tyers, 1980; Virus et al., 1981; Buck et al., 1982a). Reports that guinea pigs were more sensitive than rats to some of the biological actions of capsaicin (Jancso-Gabor et al., 1970; Glinsukon et al., 1980) and observations that guinea pigs have more numerous SP- containing primary afferents than rats (Hokfelt et al., 1977; Buck et al., 1981a; Furness et al., 1982) prompted us to assess the effects of capsaicin on sensory neuron SP levels and sensory function in guinea pigs. We observed that adult guinea pigs treated systemically with capsaicin exhibit a profound insensitivity to noxious heat in addition to marked sensory neuron SP depletion (Buck et al., 1981b). In the present report, we have characterized the dose response and time course relationships of the depletion of SP by capsaicin and investigated the effects of the compound on levels of several neuropeptides found in sensory neurons in adult guinea pigs. We have also examined the selectivity of capsaicin for certain sensory modalities in these animals.

\section{Materials and Methods}

Animal treatments. Random bred adult Hartley guinea pigs ( 350 to $450 \mathrm{gm}$ ) of either sex were obtained from a local source and used in all experiments. Animals were injected with capsaicin (Sigma Chemical Co., St. Louis, MO) subcutaneously at the back of the neck. The injection vehicle $(2 \mathrm{ml} / \mathrm{kg})$ consisted of $10 \%$ ethanol:10\% Tween $80: 80 \%$ saline. The capsaicin was first dissolved in a mixture of the appropriate amounts of ethanol and Tween 80 and the saline was then added with stirring. Suspensions were stirred continuously during use. Control animals received an equivalent amount of injection vehicle only. After the first capsaicin injection, animals were placed for $30 \mathrm{~min}$ in a chamber gassed with $95 \%$ $0_{2}: 5 \% \mathrm{CO}_{2}$ and a mist of $0.75 \%$ isoproterenol hydrochloride to prevent fatalities from capsaicin-induced bronchoconstriction. There was complete tachyphylaxis to the bronchoconstrictor action of subsequent capsaicin injections. In one experiment, we determined that the isoproterenol mist treatment had no effect on primary afferent SP levels or on the depleting actions of capsaicin in guinea pigs.

Tissue extraction. Animals were killed by decapitation and the spinal column was removed en bloc and placed for $10 \mathrm{~min}$ in ice-cold saline. The $\mathrm{C}_{4}$ to $\mathrm{T}_{2}$ section of the spinal cord and corresponding dorsal roots plus ganglia (DRG) were dissected, taking care to keep the tissues chilled at all times. The cord and pooled DRG from each animal were frozen on dry ice after which the former was bisected into dorsal and ventral portions at the level of the central canal. Tissues were weighed frozen and stored at $-60^{\circ} \mathrm{C}$ until extraction. For the extraction of $\mathrm{SP}$, somatostatin, and vasoactive intestinal polypeptide (VIP), the tissues were homogenized with a Polytron in ice-cold $2 \mathrm{~N}$ acetic acid in polypropylene tubes. The homogenates were centrifuged for $15 \mathrm{~min}$ at $10,000 \times \mathrm{g}$ and aliquots of the supernatant were placed in polypropylene culture tubes, frozen, and lyophilized. For extraction of cholecystokinin (CCK), portions of the tissues were homogenized in distilled water and the homogenates were placed in a boiling water bath for $\mathbf{1 5}$ min (Larsson and Rehfeld, 1979). These homogenates were then processed in the same manner as above for the other neuropeptides.

$S P$ radioimmunoassay. Antiserum (TG-SP 2-5) produced in rabbits inoculated with bovine thyroglobulincoupled SP was employed in the radioimmunoassay 
(RIA). Lyophilized tissue sample aliquots were dissolved in RIA buffer $(0.05 \mathrm{M}$ phosphate in saline containing $1 \%$ bovine serum albumin and $1 \%$ sodium azide) and centrifuged for $10 \mathrm{~min}$ at $10,000 \times \mathrm{g}$ to remove sediment. A portion of the dissolved sample was incubated overnight in the presence of antiserum (1:80,000 final dilution) and approximately $10,000 \mathrm{cpm}$ of $\left[{ }^{125} \mathrm{I}\right] \mathrm{Tyr}^{8}-\mathrm{SP}$ (New England Nuclear, Boston, MA) in a final incubation volume of $400 \mu$ l. Separation of the unbound tracer was accomplished by the addition of $500 \mu \mathrm{l}$ of a charcoal-dextran slurry $(0.2 \mathrm{M}$ glycine buffer (pH 8.8) containing $0.5 \%$ Norit-A charcoal and $0.25 \%$ dextran T70) and centrifugation for $15 \mathrm{~min}$ at $1,000 \times \mathrm{g}$. All aspects of the RIA were carried out at $4^{\circ} \mathrm{C}$ in polypropylene culture tubes. Cross-reactivity of the SP antiserum was determined by testing neuropeptides and SP fragments (Beckman Bioproducts, Palo Alto, CA; Peninsula Laboratories, Belmont, CA; or Vega Biochemicals, Tucson, AZ) in the RIA.

High pressure liquid chromatography of lissue extracts. SP tissue immunoreactivity was characterized by reversed phase high pressure liquid chromatography (HPLC). A Waters Associates (Milford, MA) system consisting of two Model 6000 Solvent Delivery Systems, Model U6K Injector with a 2-ml loop, Model $441 \mathrm{Ab}$ sorbance Detector $(210 \mathrm{~nm})$, and Model 660 Solvent Programmer was used. A $5-\mu \mathrm{m}$ ODS $0.45 \mathrm{~cm} \times 25 \mathrm{~cm}$ column (Bio-Rad Laboratories, Richmond, CA) was employed for separations with a mobile phase of aqueous $0.01 \mathrm{~N}$ trifluoroacetic acid and acetonitrile. Lyophilized tissue extracts were dissolved in $0.1 \mathrm{~N}$ acetic acid and a portion was chromatographed in a curvilinear gradient (7) of $25 \%$ acetonitrile to $65 \%$ acetonitrile over $45 \mathrm{~min}$. The flow rate was $2 \mathrm{ml} / \mathrm{min}$. Fractions were collected every $0.5 \mathrm{~min}$ and these were then frozen, lyophilized, and assayed in the SP RIA as described above. Peptide standards were similarly chromatographed to determine the elution time of each. SP sulfoxide, an oxidation product of SP formed during acetic acid extractions (Floor and Leeman, 1980), was prepared according to the method of Murphy et al. (1982).

Somatostatin RIA. A portion of each dissolved tissue sample was assayed for somatostatin using a RIA kit (Immuno Nuclear Corp., Stillwater, MN). The somatostatin antiserum in the kits had reported cross-reactivities of less than $0.01 \%$ with each of the peptides $\beta$-endorphin, SP, Leu-enkephalin, Met-enkephalin, Arg-vasopressin, Lys-vasopressin, oxytocin, luteinizing hormone-releasing factor, insulin, glucagon, thyrotropin-releasing hormone, and VIP.

VIP and CCK RIAs. Tissue levels of VIP and CCK were determined by RIA using previously characterized antisera. The VIP antiserum was C-terminal directed with cross-reactivities of $100 \%$ with VIP-(7-28) and VIP(18-28), $10 \%$ with VIP-(1-22), and less than $1 \%$ with each of the peptides secretin, glucagon, gastric inhibitory peptide, and somatostatin (Furness et al., 1981). Waterextracted tissue samples were dissolved and a portion was assayed for $\mathrm{CCK}$ with an antiserum that recognizes molecular forms of CCK and gastrin larger than the Cterminal tetrapeptide (Walsh et al., 1982).

Sensory function testing. Nociceptive heat sensitivity was assessed by a hot plate test and by a skin flinch test. In the hot plate test, the time required for an animal to step down $3 \mathrm{~cm}$ with all four limbs from the hot surface $\left(63^{\circ} \mathrm{C}\right.$ held constant with a variable transformer) of a food warmer tray was measured. The cutoff time in the test was $45 \mathrm{sec}$ and each animal was tested only one time. In the skin flinch test, a 1-cm beam of light from a 500W projector lamp was shined on bared (shaved and denuded with a cream depilatory) skin of the back from a distance of $3 \mathrm{~cm}$. The time until a recoil occurred in the area illuminated by the light was determined. The cutoff time in the skin flinch test was $30 \mathrm{sec}$ and each animal was tested only one time.

Non-nociceptive heat sensitivity was determined by bringing the tip of a fully heated soldering iron in a perpendicular plane to a point $1 \mathrm{~cm}$ above the bared skin of the back. The presence or absence of a skin flick below the tip within 5 sec was noted. With the use of a goldplated thermistor and a telethermometer, it was determined that such a maneuver raised the surface temperature to no more than $50^{\circ} \mathrm{C}$ in 5 sec.

Sensitivity to chemical irritants was determined by placing one drop of a $1 \%$ solution of zingerone (Pfaltz \& Bauer, Stamford, CT) onto the cornea of one eye and noting the presence or absence of vocalization and/or wiping of the eye with a limb. Control animals reacted with this behavior immediately, but for no longer than $15 \mathrm{sec}$. Similar application of a drop of saline onto the eye produced no response in guinea pigs.

Responsiveness to touch was assessed by determining the number of the smallest nylon filament on a Von Frey aesthesiometer (Stoelting Co., Chicago, IL) which elicited a skin flick when touched to the bared skin of the back.

Sensitivity to nociceptive pressure was measured by determining the volume of air compression required to elicit vocalization and/or a foot jerk when the plunger in a sealed 3-ml syringe was squeezed against the top of a rear foot on a table surface.

Nociceptive cold sensitivity was determined by measuring the escape latency from the top of a $20 \mathrm{~cm} \times 20$ $\mathrm{cm}$ sheet of dry ice. The time required for an animal to step down $3 \mathrm{~cm}$ with all four limbs when placed in the center of the sheet was noted. The cutoff time in the test was $15 \mathrm{sec}$ and each animal was tested only one time. Guinea pigs used in this test were not subjected to the hot plate test and vice versa in order to prevent the two tests from influencing each other.

Non-nociceptive cold sensitivity was assessed in each animal by bringing a $1-\mathrm{cm}$ square piece of dry ice in a perpendicular plane to a point $1 \mathrm{~cm}$ above the bared skin of the back and noting the presence or absence of a skin flick below the ice within $5 \mathrm{sec}$. With the use of a goldplated thermistor and a telethermometer, it was determined that such a maneuver lowered the surface temperature to $15^{\circ} \mathrm{C}$ in $5 \mathrm{sec}$.

For testing sensitivity to vibration, an electric vibrator was touched to the spine in the bared area of the back and the presence or absence of a startle response (quick body jerk and/or squirming) was noted. Touching the spine with the vibrator when it was not vibrating elicited little or nor startle response in the animals. 
Statistical analysis. Differences between animal groups in peptide levels and in the sensory testing where parametric data were obtained were tested with the Student's $t$ test. For nonparametric data obtained in some sensory tests, a $2 \times 2$ contingency table was used. In the tests for nociceptive heat and cold sensitivity where some animals reached the cutoff times, a Wilcoxon-Mann-Whitney rank sum test was employed. In all statistical analyses, a $p$ value of 0.05 or less was required for significance.

\section{Results}

Characteristics of SP RIA. A 1:80,000 dilution of the SP antiserum bound $35 \%\left(B_{\max }\right)$ of the added $\left[{ }^{125} \mathrm{I}\right] \mathrm{Tyr}^{8}{ }_{-}$ SP in the absence of authentic SP or tissue sample. Nonspecific apparent binding in the absence of antiserum was never greater than $5 \%$ of the total added cpm. The RIA had a sensitivity of $10 \mathrm{fmol}$ of SP in $200 \mu \mathrm{l}$ of sample. The standard curve for displacement of tracer by authentic SP was routinely linear (correlation coefficient $=-0.990$ or better $)$ between $10 \mathrm{fmol}(13.5 \mathrm{pg})$ and $1 \mathrm{pmol}$ (1.4 ng) of SP (Fig. 1). The interassay coefficient of variation was less than $10 \%$ for each of the linear standard curve parameters slope, $y$ intercept, and correlation coefficient, and for the ratio $B / B_{\max }$ (amount of tracer bound to antibody in the presence of displacer divided by $B_{\max }$ ) for samples containing either $10 \mathrm{fmol}$ or 1 pmol of SP. In the RIA, $10 \%$ and $90 \%$ displacement of tracer were considered the minimum and maximum limits, respectively, outside of which a tissue sample was reassayed at a dilution sufficient to bring it to within these limits.

The SP antiserum possessed cross-reactivity of less than $0.001 \%$ with each of the neuropeptides somatostatin, bombesin, bradykinin, VIP, pentagastrin, CCK octapeptide, neurotensin, thyrotropin-releasing hormone, angiotensin II, $\alpha-, \beta$-, and $\gamma$-endorphin, Leu ${ }^{5}-\beta$-endorphin, des-Tyr- $\gamma$-endorphin, dynorphin-(1-13), Met-enkephalin, and $\mathrm{D}-\mathrm{Ala}^{2}$-Leu-enkephalinamide. The curves for displacement of tracer by SP-(2-11) and SP-(3-11) were shifted rightward from the SP curve by an order of

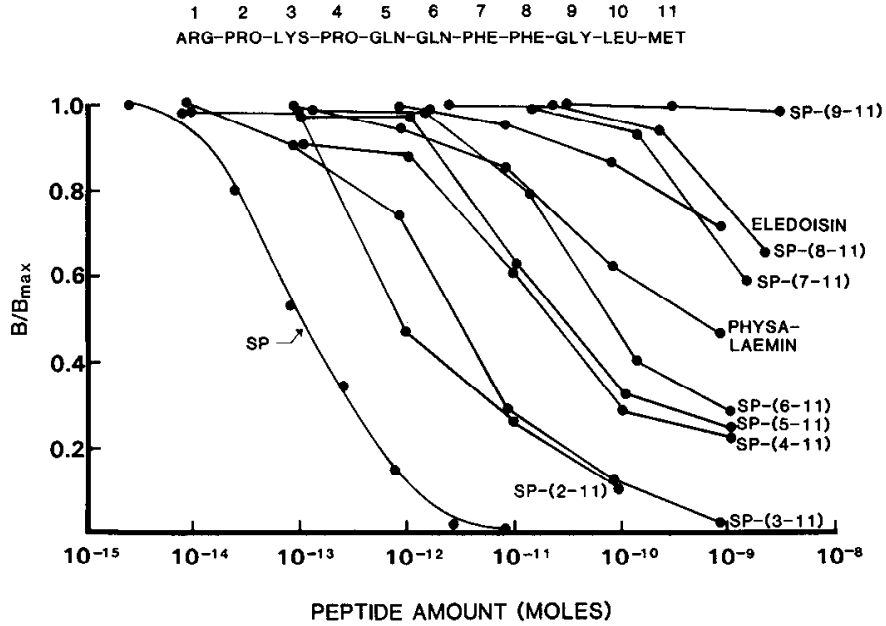

Figure 1. Cross-reactivity of SP-related peptides in the SP RIA. The indicated amount of each peptide was assayed in the RIA as described under "Materials and Methods." The amino acid sequence of SP is shown above the graph.

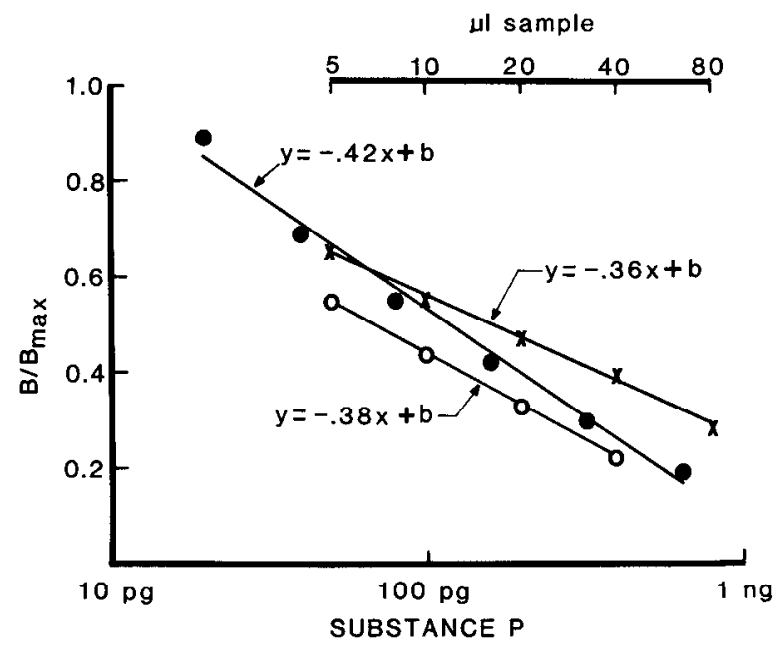

Figure 2. Comparison of tissue extract dilutions with SP standard curve. The indicated amount of dissolved tissue extract was assayed in the SP RIA as described under "Materials and Methods." All three curves were obtained from the same assay. O, SP; $\mathrm{O}$, spinal cord; $X, \mathrm{DRG}$. The best fit lines are shown along with the equation for each. Correlation coefficients were -0.993 for the SP curve, -0.999 for the spinal cord curve, and -0.996 for the DRG curve.

magnitude indicating importance of the $N$-terminal Arg for recognition by the SP antiserum. The curves for SP(4-11), SP-(5-11), and SP-(6-11) were shifted rightward by another order of magnitude implicating $\mathrm{Lys}^{3}$ as an additional recognition site. $\mathrm{Gln}^{6}$ and $\mathrm{Phe}^{8}$ were also of minor importance as sites. Physalaemin and eledoisin, which have the same $\mathrm{C}$-terminal tripeptide sequence as SP, exhibited only slight cross-reactivity with the SP antiserum (Fig. 1). Lee and co-workers (1980) have also produced a SP antiserum for which $\mathrm{Arg}^{1}$ of SP was the primary recognition site.

Characterization of SP tissue immunoreactivity. When various dilutions of a spinal cord sample and a DRG sample from a normal guinea pig were assayed in the SP RIA, the slopes of the displacement curves produced were slightly less steep than that for authentic SP (Fig. 2).

The HPLC method utilized in our study separated SP from six of its C-terminal fragments and from SP sulfoxide (Fig. 3). The elution order was SP sulfoxide, SP(5-11), SP-(4-11), SP-(6-11), SP-(3-11), SP-(7-11), SP(2-11), and SP. The earliest elution time was $11.5 \mathrm{~min}$ (SP sulfoxide) and the latest elution time was $25.2 \mathrm{~min}$ (SP). SP eluted 3.5 min away from the nearest fragment, the decapeptide SP-(2-11). When portions of dissolved DRG and spinal cord samples were chromatographed and the fractions were assayed by RIA, the profiles shown in Figure 4 were obtained. In the DRG sample, $65 \%$ of the immunoreactivity co-eluted with either SP or SP sulfoxide. In the spinal cord sample, $81 \%$ of the immunoreactivity co-eluted with these two peptides. Small amounts of immunoreactivity eluted close to the times of some C-terminal SP fragments, but in view of the low cross-reactivity of the fragments with the antiserum (see above), it is unlikely that they constitute this tissue immunoreactivity. 
The identity of the molecules being measured by RIA is only as absolute as the specificity of the antisera being used. The immunoreactivity detected may be the peptide in question or it may be some cross-reacting material and should thus be considered as simply immunoreactivity. For simplicity, we have referred to our results in terms of the peptides of interest.

Dose response and time course characteristics of $S P$ depletion. As shown in Figure 5, a single dose of $1 \mathrm{mg} / \mathrm{kg}$ of capsaicin had no effect on SP levels in dorsal cord or in DRG for up to 10 days after injection. A dose of 2.5 $\mathrm{mg} / \mathrm{kg}$ produced a progressive decrease in SP levels that was significant at 4 days (38\% decrease) and 10 days (70\% decrease) after injection. A $5-\mathrm{mg} / \mathrm{kg}$ dose of capsaicin decreased DRG SP levels as early as 2 days $(32 \%$ decrease) and for as long as 10 days ( $74 \%$ decrease) after treatment. Neither of these two latter doses produced consistently significant SP depletion in the dorsal cord of the guinea pig. A single $50-\mathrm{mg} / \mathrm{kg}$ dose of capsaicin produced a decrease in SP in both dorsal cord and DRG as soon as $12 \mathrm{hr}$ after injection. In DRG, the SP level was reduced by $42 \%$ at $12 \mathrm{hr}$ and this depletion was maximal ( $80 \%$ decrease) by 4 days. Similarly, $50 \mathrm{mg} / \mathrm{kg}$

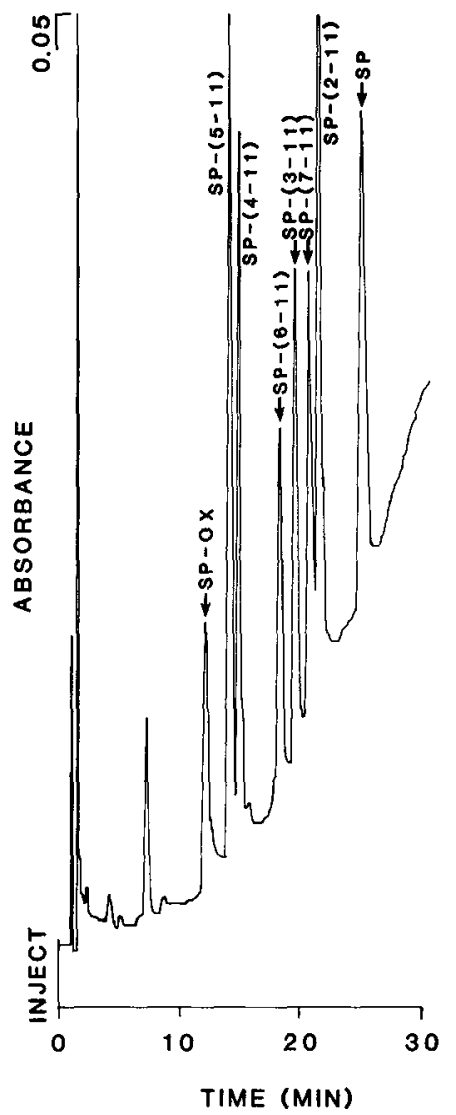

Figure 3. HPLC chromatogram of SP, SP fragments, and SP sulfoxide $(S P-O X)$. Peptides were chromatographed in a curvilinear gradient of $25 \%$ acetonitrile to $65 \%$ acetonitrile in 0.01 $\mathrm{N}$ trifluoroacetic acid (45 min). A mixture containing 0.5 to 1 $\mu \mathrm{g}$ of each peptide was injected. The elution position of each peptide was determined by chromatographing each individually. The peak at $7.5 \mathrm{~min}$ was an unknown contaminant of SP-(3-11).

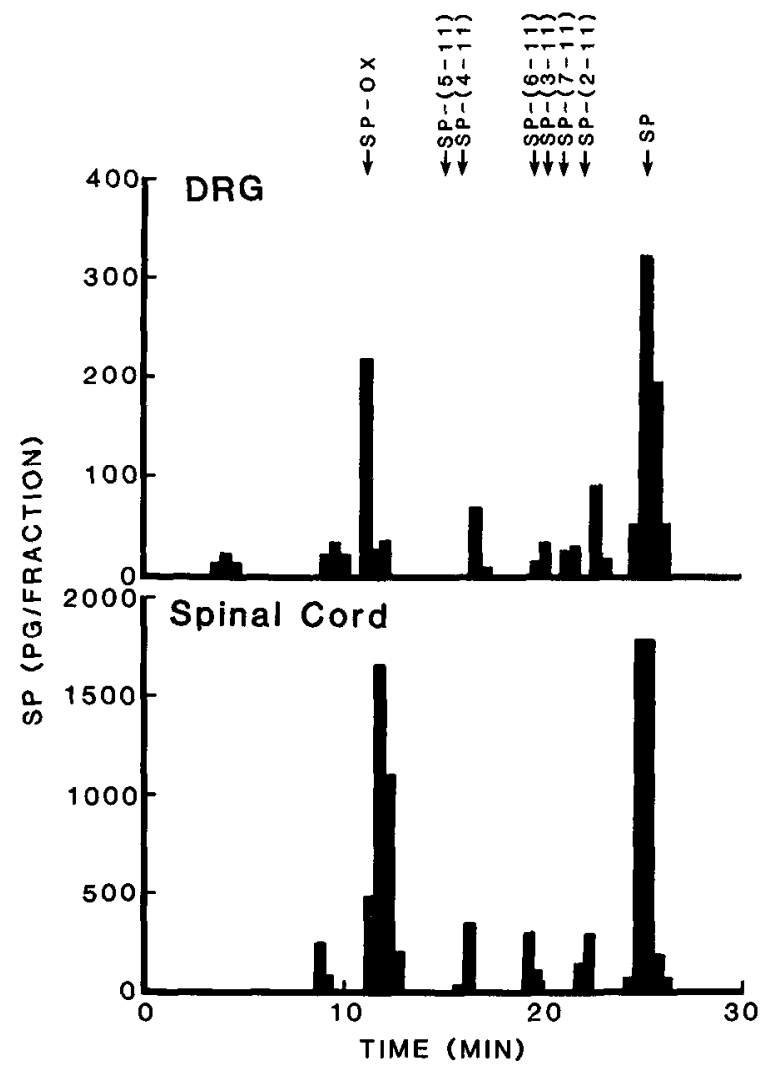

Figure 4. HPLC elution profiles of SP immunoreactivity in tissues. A portion of DRG extract (top) or spinal cord extract (bottom) was chromatographed as in Figure 3. Fractions were collected every $0.5 \mathrm{~min}$ and assayed in the SP RIA as described under "Materials and Methods." The DRG extract was dissolved in $500 \mu \mathrm{l}$ of $0.1 \mathrm{~N}$ acetic acid and $100 \mu \mathrm{l}$ were injected. The spinal cord extract was dissolved in $1.0 \mathrm{ml}$ of $0.1 \mathrm{~N}$ acetic acid and $50 \mu \mathrm{l}$ were injected.

of capsaicin reduced the SP level in dorsal cord by $20 \%$ at $12 \mathrm{hr}$, and this depletion was essentially maximal (35\% decrease) by 4 days. A single $10-\mathrm{mg} / \mathrm{kg}$ dose of capsaicin produced the same amount of depletion as the $50-\mathrm{mg} / \mathrm{kg}$ dose in both tissues at 10 days after treatment (Fig. 5).

We also observed that the single $10-\mathrm{mg} / \mathrm{kg}$ dose of capsaicin produced a doubling $(p<0.05)$ of the hot plate escape latency and obliteration $(p<0.01)$ of sensitivity to zingerone 10 days after treatment. The $5-\mathrm{mg} / \mathrm{kg}$ capsaicin dose had no effect on hot plate latencies 2,4 , or 10 days after treatment, but this dose produced total insensitivity $(p<0.01)$ to zingerone at all of these times. Sensory function at times shorter than 2 days or at lower doses than $5 \mathrm{mg} / \mathrm{kg}$ was not assessed.

Effect of capsaicin on neuropeptide levels 4 and 10 days after treatment. Treatment of guinea pigs with a cumulative systemic dose of $350 \mathrm{mg} / \mathrm{kg}$ of capsaicin depleted DRG SP by $88 \%, 4$ days after dosing (Table I). In this experiment, the SP level was not affected in the dorsal cord at the same time point. Levels of somatostatin and VIP were not altered in DRG, dorsal cord, or ventral cord by the treatment. The level of CCK in DRG was reduced by $50 \%$ and in the ventral cord by $60 \%$, but 
there was no effect on CCK in the dorsal cord in this experiment (Table I).

Ten days after a cumulative dose of $950 \mathrm{mg} / \mathrm{kg}$ of capsaicin, SP was depleted by $91 \%$ in DRG and by $32 \%$ in the dorsal cord. At the same time, there was no effect of capsaicin on levels of somatostatin, VIP, or CCK in sensory neurons of the adult guinea pig (Table I).

Effect of capsaicin on neuropeptide levels and on sensory function at 10 weeks. Treatment of guinea pigs with a single $50-\mathrm{mg} / \mathrm{kg}$ dose of capsaicin produced a depletion

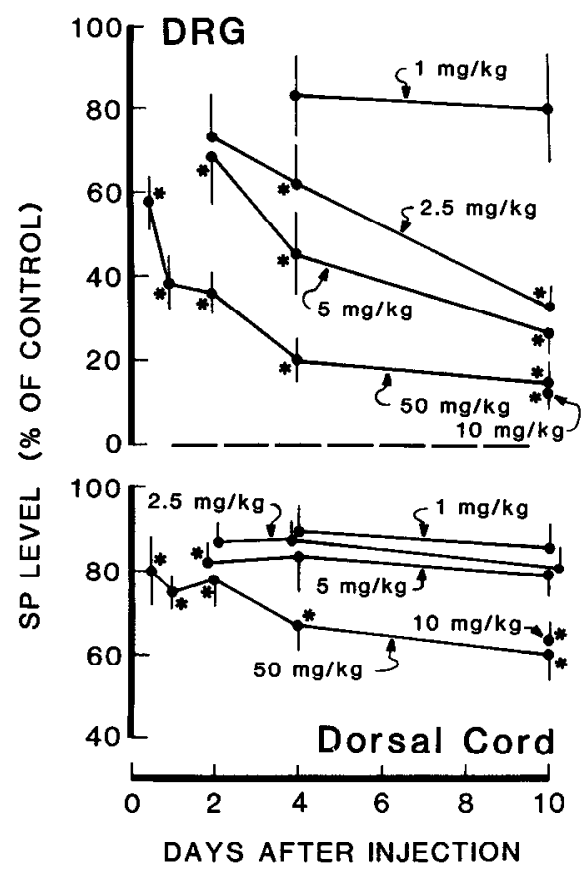

Figure 5. Dose response and time course characteristics of SP depletion. Animals were treated with single doses of capsaicin as indicated. Top, DRG; bottom, dorsal spinal cord. Values are mean \pm SEM for $n=5$ to 10 animals. $*, p<0.05$ compared to control. In the experiments depicted, control SP levels ranged from $36.7 \pm 7.8$ to $63.0 \pm 8.0 \mathrm{pmol} / \mathrm{gm}$ in DRG and from $385.2 \pm 36.6$ to $675.4 \pm 82.6 \mathrm{pmol} / \mathrm{gm}$ in dorsal cord. of primary afferent SP that was still present 10 weeks later (Table II). The level of the peptide was reduced by $77 \%$ in DRG and by $37 \%$ in dorsal cord. At the same time, there was no effect on the level of somatostatin in DRG and there was a small increase $(18 \%)$ in the level in the dorsal cord. Levels of VIP and CCK were not measured in this experiment. At 10 weeks after the 50$\mathrm{mg} / \mathrm{kg}$ dose, the animals showed reduced sensitivity to nociceptive heat in the hot plate test and complete insensitivity to the irritating effects of zingerone (Table II).

Selectivity of the effects of capsaicin on sensory function. When guinea pigs were treated with a high dose regimen of capsaicin, the compound produced sensory deficits that were selective for certain sensory modalities (Table III). Capsaicin increased the escape latencies in all treated animals in both the hot plate and skin flinch tests of nociceptive heat sensitivity. In addition, all treated animals were completely insensitive to non-nociceptive heat and to chemical irritation of the cornea. At the same time, the modalities of touch, pressure (nociceptive), cold (both non-nociceptive and nociceptive), and vibration were not affected by the capsaicin treatment (Table III). The capsaicin-treated animals displayed no behavioral or motor deficits that were apparent on gross observation.

Selectivity of the effects of morphine on sensory function. A single $10-\mathrm{mg} / \mathrm{kg}$ dose of morphine sulfate reduced the sensitivity in guinea pigs to nociceptive heat, nociceptive chemical, nociceptive pressure, and nociceptive cold stimuli (Table IV). Morphine also slightly reduced the sensitivity to touch in the treated animals. All treated animals reached the 45 -sec cutoff in the hot-plate test and four of five treated animals reached the 15 -sec cutoff in the dry ice sheet test. The responsiveness to zingerone and to nociceptive pressure was also markedly attenuated (Table IV). In addition to establishing the pattern of the effects of morphine on sensory responsiveness, the results with the opiate confirm the nociceptive character of the tests we have developed to assess the sensitivity of guinea pigs to various nociceptive stimuli. The mor-

TABLE I

Effect of capsaicin on sensory neuron neuropeptide levels 4 and 10 days after dosing

Guinea pigs were treated with two consecutive daily doses of 100 and $250 \mathrm{mg} / \mathrm{kg}$ of capsaicin and killed 4 days (top half of table) after the last injection, or were treated with five consecutive daily doses of $50,100,200,200$, and $400 \mathrm{mg} / \mathrm{kg}$ and killed 10 days (bottom of table) after the last injection. Values are meam \pm SEM for $n=4$ to 6 animals.

\begin{tabular}{|c|c|c|c|c|c|c|}
\hline \multirow[b]{2}{*}{ Peptide } & \multicolumn{3}{|c|}{ Control } & \multicolumn{3}{|c|}{ Capsaicin } \\
\hline & DRG & $\begin{array}{c}\text { Dorsal } \\
\text { cord }\end{array}$ & $\begin{array}{l}\text { Ventral } \\
\text { cord }\end{array}$ & DRG & $\begin{array}{c}\text { Dorsal } \\
\text { cord }\end{array}$ & $\begin{array}{l}\text { Ventral } \\
\text { cord }\end{array}$ \\
\hline & & & & & & \\
\hline SP & $31.0 \pm 6.8$ & $259.5 \pm 32.5$ & $26.9 \pm 5.1$ & $3.8 \pm 1.0^{\alpha}$ & $222.3 \pm 24.4$ & $33.2 \pm 8.5$ \\
\hline Somatostatin & $1.8 \pm 0.6$ & $52.0 \pm 4.3$ & $26.7 \pm 0.9$ & $1.1 \pm 0.2$ & $50.3 \pm 1.2$ & $24.5 \pm 4.4$ \\
\hline VIP & $1.7 \pm 0.5$ & $3.5 \pm 0.6$ & $2.4 \pm 0.4$ & $1.9 \pm 0.4$ & $2.5 \pm 0.8$ & $1.7 \pm 0.2$ \\
\hline CCK & $4.2 \pm 0.3$ & $13.4 \pm 1.6$ & $2.2 \pm 0.3$ & $2.1 \pm 0.6^{a}$ & $13.0 \pm 2.1$ & $0.9 \pm 0.2^{a}$ \\
\hline SP & $70.5 \pm 16.4$ & $307.9 \pm 30.0$ & $25.0 \pm 2.6$ & $6.2 \pm 0.8^{a}$ & $210.9 \pm 17.5^{b}$ & $21.4 \pm 2.7$ \\
\hline Ssomatostatin & $3.8 \pm 0.5$ & $18.2 \pm 2.4$ & $9.5 \pm 0.7$ & $3.0 \pm 0.4$ & $19.1 \pm 1.0$ & $9.4 \pm 0.8$ \\
\hline VIP & $1.7 \pm 0.3$ & $1.1 \pm 0.2$ & $1.7 \pm 0.3$ & $1.6 \pm 0.1$ & $1.8 \pm 0.5$ & $1.6 \pm 0.4$ \\
\hline CCK & $1.8 \pm 0.3$ & $6.3 \pm 1.0$ & $0.4 \pm 0.04$ & $1.5 \pm 0.3$ & $4.5 \pm 0.7$ & $0.4 \pm 0.05$ \\
\hline
\end{tabular}

${ }^{a} p<0.01$ compared to control.

${ }^{b} p<0.05$ compared to control. 
TABLE II

Effect of capsaicin on sensory neuron neuropeptide levels and on nociceptive thermal and chemical sensitivity 10 weeks after dosing Guinea pigs were treated with a single dose of $50 \mathrm{mg} / \mathrm{kg}$ of capsaicin, tested for sensory function 69 days later, and then killed $24 \mathrm{hr}$ later. Values are mean \pm SEM for $n=5$ to 6 animals.

\begin{tabular}{|c|c|c|c|c|c|c|c|}
\hline \multirow[b]{2}{*}{ Peptide } & \multicolumn{3}{|c|}{ Control } & & \multicolumn{3}{|c|}{ Capsaicin } \\
\hline & DRG & $\begin{array}{c}\text { Dorsal } \\
\text { cord }\end{array}$ & $\begin{array}{l}\text { Ventral } \\
\text { cord }\end{array}$ & & DRG & $\begin{array}{c}\text { Dorsal } \\
\text { cord }\end{array}$ & $\begin{array}{l}\text { Ventral } \\
\text { cord }\end{array}$ \\
\hline & \multicolumn{7}{|c|}{$\mathrm{pmol} / \mathrm{gm}$} \\
\hline Somatostatin & $1.0 \pm 0.2$ & $29.0 \pm 1.7$ & $15.0 \pm 1.3$ & & $1.5 \pm 0.5$ & $34.1 \pm 1.3^{6}$ & $17.4 \pm 0.7$ \\
\hline Hot plate test & \multirow{2}{*}{\multicolumn{3}{|c|}{$\begin{array}{c}25.1 \pm 2.7 \mathrm{sec} \\
100 \% \text { responding }\end{array}$}} & & \multirow{2}{*}{\multicolumn{3}{|c|}{$\begin{array}{c}4 / 5 \text { animals }>45 \sec ^{a} \\
0 \% \text { responding }\end{array}$}} \\
\hline Zingerone on cornea & & & & & & & \\
\hline
\end{tabular}

${ }^{a} p<0.01$ compared to control.

${ }^{b} p<0.05$ compared to control.

TABLE III

Selectivity of the effects of capsaicin on sensory function in the guinea pig

Animals were treated with five consecutive daily doses of $50,100,200,200$, and $400 \mathrm{mg} / \mathrm{kg}$ of capsaicin and tested for sensory function 10 to 11 days after the last injection. Values are mean \pm SEM or percentage responding for $n=5$ to 10 animals.

\begin{tabular}{|c|c|c|c|}
\hline Test & Function & Control & Capsaicin \\
\hline Hot plate & Nociceptive heat & $18.6 \pm 5.8 \mathrm{sec}$ & All $>45 \sec ^{a}$ \\
\hline Skin flinch & Nociceptive heat & $12.5 \pm 1.3 \mathrm{sec}$ & All $>30 \sec ^{a}$ \\
\hline Heat probe & Non-nociceptive heat & $100 \%$ & $0 \%^{a}$ \\
\hline Aesthesiometer & Touch & $5.8 \pm 0.9$ units & $4.9 \pm 1.1$ units \\
\hline Paw press & Nociceptive pressure & $0.7 \pm 0.1 \mathrm{ml}$ & $0.8 \pm 0.1 \mathrm{ml}$ \\
\hline Vibrator & Vibration & $100 \%$ & $80 \%$ \\
\hline
\end{tabular}

${ }^{a} p<0.01$.

TABLE IV

Selectivity of the effects of morphine on sensory function in the guinea pig

Animals were treated with $10 \mathrm{mg} / \mathrm{kg}$ of morphine sulfate intraperitoneally $1 \mathrm{hr}$ before sensory testing. Values are mean \pm SEM or percentage responding for $n=5$ to 10 animals.

\begin{tabular}{|c|c|c|c|}
\hline Test & Function & Control & Morphine \\
\hline Hot plate & Nociceptive heat & $12.5 \pm 2.4 \mathrm{sec}$ & All $>45 \mathrm{sec}^{a}$ \\
\hline Heat probe & Non-nociceptive heat & $100 \%$ & $100 \%$ \\
\hline $\begin{array}{l}\text { Zingerone on cor- } \\
\text { nea }\end{array}$ & Nociceptive chemical & $100 \%$ & $20 \%{ }^{u}$ \\
\hline Aesthesiometer & Touch & $2.4 \pm 0.5$ units & $\begin{array}{l}3.8 \pm 0.2 \text { un- } \\
\text { its }^{b}\end{array}$ \\
\hline Paw press & Nociceptive pressure & $1.2 \pm 0.2 \mathrm{ml}$ & $0.4 \pm 0.1 \mathrm{ml}^{a}$ \\
\hline Vibrator & Vibration & $100 \%$ & $100 \%$ \\
\hline
\end{tabular}

$$
\begin{aligned}
& { }^{a} p<0.01 . \\
& { }^{b} p<0.05 .
\end{aligned}
$$

phine-treated animals appeared somewhat hypoactive compared to controls and this may explain the effect of morphine in the test of touch sensitivity.

Capsaicin-induced skin lesions and corneal opacities. High doses of capsaicin produced skin lesions and corneal opacities in guinea pigs. The skin lesions had the appearance of scabs with hair loss in the wound and were limited to the neck and facial area of the treated animals. The corneal opacities were characterized by a whitish clouding of the cornea that at a cumulative dose of 950 $\mathrm{mg} / \mathrm{kg}$ of capsaicin progressed to corneal ulceration with adhesion of the overlying underneath surface of the eyelid. The lesions occurred in animals housed alone the entire time; thus they were not caused by fighting. At all dose regimens of capsaicin which produced the skin and eye effects, the onset of the lesions was slow, requiring at least 2 weeks. Cumulative doses of $950 \mathrm{mg} / \mathrm{kg}$ or more produced the skin lesions in $100 \%$ of the treated animals and eye lesions in both eyes in $100 \%$ of the treated animals. In animals treated with lower dose regimens of capsaicin, the skin and eye lesions improved in condition approximately 4 weeks after their onset. 


\section{Discussion}

Characterization of tissue immunoreactivity measured in the SP RIA in the present investigation indicated that the majority of the immunoreactivity was authentic SP (including SP sulfoxide that would be formed in the tissue extraction). The immunoreactivity which did not correspond to SP or SP sulfoxide in the HPLC characterization was probably not composed of C-terminal fragments of SP and may have been responsible for the shallower slopes of the tissue extract dilution curves. The fact that as much as $85 \%$ of the DRG SP immunoreactivity could be depleted by capsaicin in guinea pigs suggests either that the HPLC characterization underestimated the amount of immunoreactivity identifiable as SP or SP sulfoxide or that there is cross-reacting material unrelated to SP which is capsaicin depletable. The low cross-reactivity of other neuropeptides with our antiserum mitigates against the latter possibility. The unidentifiable immunoreactivity seen by HPLC may be fragments from other than the C-terminal end of SP (e.g., N-terminal fragments) which would presumably be capsaicin depletable.

Our results indicate that capsaicin is potent at producing SP depletion in guinea pigs and that this effect can last for an extremely long time. The adult guinea pig may be more sensitive to the depleting actions of capsaicin than the adult rat since a single $50-\mathrm{mg} / \mathrm{kg}$ dose of capsaicin produced only a 30\% decrease in SP levels in dorsal roots and ganglia in adult rats (Lembeck and Donnerer, 1981). In addition, a total systemic dose of $125 \mathrm{mg} / \mathrm{kg}$ in adult rats reduced SP levels in DRG by only $50 \%$ (Gamse et al., 1981b). The longevity of the SP depletion that we observed in sensory neurons of the guinea pig is consistent with immunohistochemical observations of Papka et al. (1981) of SP in the hearts of capsaicin-treated guinea pigs. Adult rats treated with 125 $\mathrm{mg} / \mathrm{kg}$ of capsaicin systemically also had significant SP depletion in sensory neurons lasting as long as several months after treatment (Gamse et al., 1981b). The longlasting reduction of SP levels presumably is not due to a prolonged presence of capsaicin in neuronal tissues (Saria et al., 1982).

Our observations in adult guinea pigs indicate that capsaicin does not deplete levels of other neuropeptides found in primary afferent neurons (see Hokfelt et al., 1980; Buck et al., 1982a). After supramaximal depleting doses of capsaicin, the levels of VIP and of somatostatin in dorsal cord and DRG were not altered at either 4 days or 10 days after treatment, even though SP was maximally depleted in DRG at both times. Somatostatin was also not depleted 10 weeks after a single systemic dose of capsaicin which produced maximal SP depletion for this long. Papka and co-workers (1981) have also reported that VIP immunoreactivity in the hearts of capsaicin-treated guinea pigs is not affected at times when SP immunoreactivity is nearly obliterated. On the other hand, Gamse et al. (1981b) have detected a slight decrease in sensory neuron somatostatin levels that was short-lived compared to the effects on SP in adult rats. These results suggest that there may be some differences between adult guinea pigs and adult rats in the biochem- ical consequences of the actions of capsaicin on sensory neurons. It is clear that there are marked differences in the neurochemical effects of capsaicin in adult guinea pigs compared to neonatal rats where the compound depletes immunoreactive VIP, somatostatin, and CCK as well as SP in sensory neurons (Jancso et al., 1981; Kessler and Black, 1981; Nagy et al., 1981b).

We observed a 50\% decrease in CCK levels in DRG and in the ventral cord 4 days after capsaicin treatment of adult guinea pigs. Ten days after a high dose regimen of capsaicin, these decreases were no longer present. In rats treated neonatally with capsaicin, it has been reported that CCK determined by immunohistochemical means is depleted (Jancso et al., 1981; Schultzberg et al., 1982). Our antiserum may have revealed a transient effect of capsaicin on some CCK-containing sensory neurons, similar to the transient effect that has been observed on somatostatin-containing afferents in the adult rat (Gamse et al., 1981b). These capsaicin-sensitive CCK-containing neurons could be among those unmyelinated afferent fibers that have been discovered to send their central processes to the spinal cord via the ventral spinal roots (Coggeshall et al., 1974; Hosobuchi, 1980). Alternatively, the transient effects of capsaicin on sensory neuron CCK levels might be related to the recent observation that SP and CCK coexist in some DRG cells (Dalsgaard et al., 1982). Additional studies employing other antibodies and immunohistochemical techniques will be necessary to verify our results and to elaborate the relationship of the effects of capsaicin on SP levels to the effects on CCK levels. Our results with CCK, coupled with those discussed above for VIP and somatostatin, indicate that capsaicin has effects in SP-containing sensory neurons in the adult guinea pig that do not occur in other known peptide-containing afferents, at least as manifested by prolonged peptide depletion.

It is interesting to note that capsaicin doses of 2.5 and $5 \mathrm{mg} / \mathrm{kg}$ produced maximal SP depletion in DRG without producing maximal depletion in the dorsal spinal cord of guinea pigs. A dissociation between the effects of capsaicin on SP levels in dorsal root ganglia and in dorsal cord has also been reported in adult rats where SP levels were elevated above controls in ganglia at times when levels in the dorsal cord were reduced (Lembeck and Donnerer, 1981). These observations indicate that SP depletion in the sensory neuron cell bodies precedes depletion in the cord and/or that the mechanism of the depletion is different in the two locations. The apparent ability of capsaicin to interfere with the axoplasmic transport of nerve growth factor in peripheral processes of some sensory neurons (Miller et al., 1982) and the ability of the compound to release neuropeptides, as well as produce other biochemical effects, in the spinal cord (Gamse et al., 1981a; Nagy et al., 1981a) suggest that both alternatives apply to the SP depletion by capsaicin. Thus, SP depletion at the central processes of primary afferents involves, at least in part, the release of SP whereas the depletion in cell bodies involves an effect on the intracellular processing of the peptide.

In contrast to adult rats treated systemically with capsaicin (Hayes and Tyers, 1980; Buck et al., 1982a; Gamse, 1982), adult guinea pigs treated with the agent 
exhibit a marked insensitivity to nociceptive thermal stimulation (Buck et al., 1981b). The present results indicate that low doses of capsaicin can produce this insensitivity and that it can persist for a long time. Nonnociceptive heat sensitivity and sensitivity to chemical irritation are also markedly reduced by capsaicin in guinea pigs. Various other sensory modalities, including other forms of nociceptive stimuli, are not affected by capsaicin. This pattern of sensory selectivity is different from that of the opiate analgesic agent, morphine, which had effects on all types of nociceptive sensitivity because of its actions on higher CNS centers of sensory integration. A more peripheral site of action of capsaicin was clearly indicated by the fact that application of zingerone onto the cornea of normal guinea pigs produced an immediate closure of the affected eye and wincing of the animal followed by vocalization and/or wiping of the affected eye with a limb. In capsaicin-treated animals, none of these responses occurred. In morphine-treated animals, however, the eye closure was still present but the other responses were blocked. We also observed that chemogenic insensitivity in capsaicin-treated guinea pigs could be detected at a lower dose of capsaicin than that required to produce the thermal insensitivity. This is consistent with the extreme potency of capsaicin in inducing insensitivity of the cornea of the adult rat to chemical irritation (Lembeck and Donnerer, 1981; Gamse et al., 1981b).

The major difference between adult rats and adult guinea pigs with respect to capsaicin-induced nociceptive thermal sensitivity may be related to the more numerous SP-containing sensory afferents in the guinea pig (Hokfelt et al., 1977; Buck et al., 1981a; Furness et al., 1982). Although capsaicin may produce a short-lived increase in thresholds to nociceptive thermal stimuli in adult rats (Gamse, 1982), the absence of a long-lasting change in thermal sensitivity that parallels the long-lasting marked depletion of sensory neuron SP is difficult to reconcile with the proposed role of SP in sensory neuron transduction of nociceptive thermal stimuli as studied in cats (Henry, 1976; Randic and Miletic, 1977). Similarly inconsistent with this role for SP is the recent report that an intrathecally administered SP antagonist fails to produce increased thresholds to nociceptive thermal stimuli in mice (Piercey et al., 1981). It is possible that there is some compensatory mechanism operative in rats, but not in guinea pigs, that permits thermal stimuli to still be perceived in the capsaicin-treated animals. The substantially higher sensory neuron levels of SP relative to the levels of somatostatin we consistently found in adult guinea pigs (Tables I and II) are in contrast to two reports by Gamse and co-workers (1981a, b) in which SP and somatostatin levels were identical to each other in sensory neurons of the adult rat. Thus, there seems to be a species difference in the absolute levels of SP as well as in the levels relative to another neuropeptide which may indicate different neurophysiological roles for $\mathrm{SP}$ in sensory afferents of guinea pigs compared to those of rats.

The apparent peptide specificity of the effects of capsaicin on SP in the guinea pig and the selectivity of the compound in altering only certain sensory functions implicate SP in the neurophysiology of those primary afferent neurons in the adult guinea pig which subserve non-nociceptive and nociceptive heat sensitivity and sensitivity to chemical irritation. These capsaicin-sensitive cells presumably give rise to type $\mathrm{C}$ fibers. Whether or not all these affected sensory modalities are mediated by a single class of SP-containing neuron in the guinea pig must await determination in future investigations. The corneal and skin lesions produced by capsaicin in guinea pigs are consistent with a peripheral neuropathy of sensory neurons and may be due to an altered trophic influence of these cells on target tissues (Walton, 1977).

The pattern of sensory deficits and the epithelial lesions produced by capsaicin resemble certain peripheral neuropathies in humans. For example, victims of familial dysautonomia, a disorder of the autonomic and sensory nervous systems in which SP is absent from the spinal substantia gelatinosa (Pearson et al., 1982), show diminished temperature and pain sensitivity and occasional lesions of the cornea (Brunt and McKusick, 1970). There may also be abnormalities in SP-containing sensory neurons in other forms of sensory neuropathy (Nutt et al., 1980). The capsaicin-treated guinea pig may provide a useful laboratory model for research designed at better understanding sensory neuron pathologies. Capsaicin itself promises to be an invaluable tool for studies of sensory neurophysiology and of the innervation of tissues by primary afferents. The SP depletion and consequent reduction in sensitivity to certain nociceptive stimuli that we observed in guinea pigs treated with the compound suggest that capsaicin will be of value in examining the intriguing possibility that SP innervation of diverse tissues in the body is responsible for pain sensation from these tissues.

\section{References}

Brunt, P. W., and V. A. McKusick (1970) Familial dysautonomia-A report of genetic and clinical studies with a review of the literature. Medicine 49: 343-374.

Buck, S. H., and T. F. Burks (1983) Capsaicin: Hot new pharmacological tool. Trends Pharmacol. Sci. 4: 84-87.

Buck, S. H., P. P. Deshmukh, H. I. Yamamura, and T. F. Burks (1981a) Difference between rats and guinea pigs in gastrointestinal and nervous system substance P levels. Neuropeptides 1: 383-389.

Buck, S. H., P. P. Deshmukh, H. I. Yamamura, and T. F. Burks (1981b) Thermal analgesia and substance $P$ depletion induced by capsaicin in guinea pigs. Neuroscience 6: 22172222.

Buck, S. H., M. S. Miller, and T. F. Burks (1982a) Depletion of primary afferent substance $P$ by capsaicin and dihydrocapsaicin without altered thermal sensitivity in rats. Brain Res. 233: 216-220.

Buck, S., J. H. Walsh, H. I. Yamamura, and T. F. Burks (1982b) Minireview-Neuropeptides in sensory neurons. Life Sci. 30: 1857-1866.

Cervero, F., and H. A. McRitchie (1981) Neonatal capsaicin and thermal nociception: A paradox. Brain Res. 215: 414418.

Coggeshall, R. E., J. D. Coulter, and W. D. Willis (1974) Unmyelinated axons in the ventral roots of the cat lumbosacral enlargement. J. Comp. Neurol. 153: 39-58.

Dalsgaard, C. -J., S. Vincent, T. Hokfelt, G. J. Dockray, and A. C. Cuello (1982) Immunohistochemical evidence for coexist- 
ence of cholecystokinin- and substance P-like peptides in primary sensory neurons. Soc. Neurosci. Abstr. 8: 474.

Floor, E., and S. E. Leeman (1980) Substance P sulfoxide: Separation from substance $\mathbf{P}$ by high-pressure liquid chromatography, biological and immunological activities, and chemical reduction. Anal. Biochem. 101: 498-503.

Furness, J. B., M. Costa, and J. H. Walsh (1981) Evidence for and significance of the projection of VIP neurons from the myenteric plexus to the taenia coli in the guinea pig. Gastroenterology 80: 1557-1561.

Furness, J. B., R. E. Papka, N. G. Della, M. Costa, and R. L. Eskay (1982) Substance P-like immunoreactivity in nerves associated with the vascular system of guinea-pigs. Neuroscience 7: 447-459.

Gamse, R. (1982) Capsaicin and nociception in the rat and mouse-Possible role of substance P. Naunyn-Schmiedebergs Arch. Pharmacol. 320: 205-216.

Gamse, R., P. Holzer, and F. Lembeck (1979) Indirect evidence for presynaptic location of opiate receptors on chemosensitive primary sensory neurones. Naunyn-Schmiedebergs Arch. Pharmacol. 308: 281-285.

Gamse, R., P. Holzer, and F. Lembeck (1980) Decrease of substance $P$ in primary afferent neurons and impairment of neurogenic plasma extravasation by capsaicin. Br. J. Pharmacol. 68: 207-213.

Gamse, R., D. Lackner, G. Gamse, and S. E. Leeman (1981a) Effect of capsaicin pretreatment on capsaicin-evoked release of immunoreactive somatostatin and substance $P$ from primary sensory neurons. Naunyn-Schmiedebergs Arch. Pharmacol. 316: 38-41.

Gamse, R., S. E. Leeman, P. Holzer, and F. Lembeck (1981b) Differential effects of capsaicin on the content of somatostatin, substance $P$, and neurotensin in the nervous system of the rat. Naunyn-Schmiedebergs Arch. Pharmacol. 317: 140148.

Gamse, R., A. Wax, R. E. Zigmond, and S. E. Leeman (1981c) Immunoreactive substance $\mathbf{P}$ in sympathetic ganglia: Distribution and sensitivity towards capsaicin. Neuroscience 6 : 437-441.

Gasparovic, I., S. Hadzovic, S. Hukovic, and P. Stern (1964) Contribution to the theory that substance $\mathrm{P}$ has a neurotransmitter role in sensory pathways. Med. Exp. (Hung.) 10: 303-306.

Glinsukon, T., V. Stitmunnaithum, C. Toskulkao, T. Buranawuti, and V. Tangkrisanavinont (1980) Acute toxicity of capsaicin in several animal species. Toxicon 18: 215-220.

Hayes, A. G., and M. B. Tyers (1980) Effects of capsaicin on nociceptive heat, pressure, and chemical thresholds and on substance $P$ levels in the rat. Brain Res. 189: 561-564.

Hayes, A. G., J. W. Scadding, M. Skingle, and M. B. Tyers (1981) Effects of neonatal administration of capsaicin on nociceptive thresholds in the mouse and rat. J. Pharm. Pharmacol. 33:183-185.

Henry, J. L. (1976) Effects of substance P on functionally identified units in cat spinal cord. Brain Res. 114: 439-451.

Hokfelt, T., L. -G. Elfvin, M. Schultzberg, M. Goldstein, and G. Nilsson (1977) On the occurrence of substance P-containing fibers in sympathetic ganglia. Immunohistochemical evidence. Brain Res. 132: 29-41.

Hokfelt, T., O. Johansson, A. Ljungdahl, J. M. Lundberg, and M. Schultzberg (1980) Peptidergic neurons. Nature 284: 515521.

Holzer, P., I. Jurna, R. Gamse, and F. Lembeck (1979) Nociceptive threshold after neonatal capsaicin treatment. Eur. J. Pharmacol. 58: 511-514.

Holzer, P., R. Gamse, and F. Lembeck (1980) Distribution of substance $P$ in the gastrointestinal tract-Lack of effect of capsaicin pretreatment. Eur. J. Pharmacol. 61: 303-307.
Hosobuchi, Y. (1980) The majority of unmyelinated afferent axons in human ventral roots probably conduct pain. Pain 8 : 167-180.

Hoyes, A. D., and P. Barber (1981) Degeneration of axons in the ureteric and duodenal nerve plexuses of the adult rat following in vivo treatment with capsaicin. Neurosci. Lett. 25: $19-24$.

Jancso, N. (1968) Desensitization with capsaicin and related acylamides as a tool for studying the function of pain receptors. In Pharmacology of Pain, Proceedings of the Third International Pharmacological Meeting, R. K. S. Lim, ed., pp. 33-55, Pergamon Press, Oxford.

Jancso, G., and E. Knyihar (1975) Functional linkage between nociception and fluoride-resistant acid phosphatase activity in the Rolando substance. Neurobiology 5: 42-43.

Jancso, G., and E. Kiraly (1980) Distribution of chemosensitive primary afferents in the central nervous system of the rat. J. Comp. Neurol. 190: 781-792.

Jancso, G., E. Kiraly, and A. Jancso-Gabor (1977) Pharmacologically induced selective degeneration of chemosensitive primary sensory neurones. Nature 270: 741-743.

Jancso, G., T. Hokfelt, J. M. Lundberg, E. Kiraly, N. Halasz, G. Nilsson, L. Terenius, J. Rehfeld, H. Steinbusch, A. Vergofstad, R. Elde, S. Said, and M. Brown (1981) Immunohistochemical studies on the effect of capsaicin on spinal and medullary peptide and monoamine neurons using antisera to substance $P$, gastrin-CCK. somatostatin, VIP, enkephalin, neurotensin, and 5-hydroxytryptamine. J. Neurocytol. 10: 963-980.

Jancso-Gabor, A., J. Szolcsanyi, and N. Jancso (1970) Irreversible impairment of thermoregulation induced by capsaicin and similar pungent substances in rats and guinea pigs. J. Physiol. (Lond.) 206: 495-507.

Jessell, T. M., L. L.Iversen, and A. C. Cuello (1978) Capsaicininduced depletion of substance $\mathrm{P}$ from primary sensory neurones. Brain Res. 152: 183-188.

Joo, F., J. Szolcsanyi, and A. Jancso-Gabor (1969) Mitochondrial alterations in the spinal ganglion cells of the rat accompanying the long-lasting sensory disturbance induced by capsaicin. Life Sci. 8: 621-626.

Kessler, J. A., and I. B. Black (1981) Similarities in development of substance $\mathbf{P}$ and somatostatin in peripheral sensory neurons: Effects of capsaicin and nerve growth factor. Proc. Natl. Acad. Sci. U. S. A. 78: 4644-4647.

Larsson, L. -I., and J. F. Rehfeld (1979) Localization and molecular heterogeneity of cholecystokinin in the central and peripheral nervous system. Brain Res. 165: 201-218.

Lee, C. M., P. C. Emson, and L. L. Iversen (1980) The development and application of a novel N-terminal directed substance $\mathrm{P}$ antiserum. Life Sci. 27: 535-543.

Leeman, S. E., and R. Gamse (1981) Substance P in sensory neurons. Trends Pharmacol. Sci. 2: 119-121.

Lembeck, F., and J. Donnerer (1981) Time course of capsaicininduced functional impairments in comparison with changes in neuronal substance $\mathrm{P}$ content. Naunyn-Schmiedebergs Arch. Pharmacol. 316: 240-243.

Miller, M. S., S. H. Buck, I. G. Sipes, H. I. Yamamura, and T. F. Burks (1982) Regulation of substance $\mathbf{P}$ by nerve growth factor: Disruption by capsaicin. Brain Res 250: 193-196.

Murphy, R., J. B. Furness, A. M. Beardsley, and M. Costa (1982) Characterization of substance P-like immunoreactivity in peripheral sensory nerves and enteric nerves by high pressure liquid chromatography and radioimmunoassay. Regul. Pept. 4: 203-212.

Nagy, J. I. (1982) Capsaicin's actions on the nervous system. Trends Neurosci. 5: 362-365.

Nagy, J. I., S. R. Vincent, W. A. Staines, H. C. Fibiger, T. D. Reisine, and H. I. Yamamura (1980) Neurotoxic action of 
capsaicin on spinal substance $\mathrm{P}$ neurons. Brain Res. 186: 435-444.

Nagy, J. I., P. C. Emson, and L. L. Iversen (1981a) A reevaluation of the neurochemical and antinociceptive effects of intrathecal capsaicin in the rat. Brain Res. 211: 497-502.

Nagy, J. I., S. P. Hunt, L. L. Iversen, and P. C. Emson (1981b) Biochemical and anatomical observations on the degeneration of peptide-containing primary afferent neurons after neonatal capsaicin. Neuroscience 6: 1923-1934.

Nutt, J. G., E. A. Mroz, S. E. Leeman, A. C. Williams, W. K. Engel, and T. N. Chase (1980) Substance P in human cerebrospinal fluid: Reductions in peripheral neuropathy and autonomic dysfunction. Neurology 30: 1280-1285.

Obal, F., G. Benedek, and A. Jancso-Gabor (1979) Salivary cooling, escape reaction, and heat pain in capsaicin-desensitized rats. Pflugers Arch. 382: 249-254.

Papka, R. E., J. B. Furness, N. G. Della, and M. Costa (1981) Depletion by capsaicin of substance $\mathrm{P}$-immunoreactivity and acetylcholinesterase activity from nerve fibers in the guineapig heart. Neurosci. Lett. 27: 47-53.

Papka, R. E., J. B. Furness, and M. Costa (1982) Time course of capsaicin effects on substance $P$-immunoreactive nerves in the cardiovascular system. Soc. Neurosci. Abstr. 8: 583.

Pearson, J., L. Brandeis, and A. C. Cuello (1982) Depletion of substance $\mathrm{P}$-containing axons in substantia gelatinosa of patients with diminished pain sensitivity. Nature 295: 61-63.

Piercey, M. F., L. A. Schroeder, K. Folkers, J. -C. Xu, and J. Horig (1981) Sensory and motor functions of spinal cord substance P. Science 214: 1361-1363.

Randic, M., and V. Miletic (1977) Effect of substance P in cat dorsal horn neurones activated by noxious stimuli. Brain Res. 128: 164-169.

Saria, A., G. Skofitsch, and F. Lembeck (1982) Distribution of capsaicin in rat tissues after systemic administration. J. Pharm. Pharmacol. 34: 273-275.

Scadding, J. W. (1980) The permanent anatomical effects of neonatal capsaicin on somatosensory nerves. J. Anat. 131: 473-484.

Schultzberg, M., G. J. Dockray, and R. G. Williams (1982) Capsaicin depletes CCK-like immunoreactivity detected by immunohistochemistry, but not that measured by radioimmunoassay in rat dorsal spinal cord. Brain Res. 235: 198204.

Szolcsanyi, J., A. Jancso-Gabor, and F. Joo (1975) Functional and fine structural characteristics of the sensory neuron blocking effect of capsaicin. Naunyn-Schmiedebergs Arch. Pharmacol. 287: 157-169.

Virus, R. M., and G. F. Gebhart (1979) Minireview-Pharmacologic actions of capsaicin: Apparent involvement of substance $\mathrm{P}$ and serotonin. Life Sci. 25: 1273-1284.

Virus, R. M., M. M. Knuepfer, D. Q. McManus, M. J. Brody, and G. F. Gebhart (1981) Capsaicin treatment in adult Wistar-Kyoto and spontaneously hypertensive rats: Effects on nociceptive behavior and cardiovascular regulation. Eur. J. Pharmacol. 72: 209-217.

Walsh, J. H., C. B. Lamers, and J. E. Valenzuela (1982) Cholecystokinin-octapeptidelike immunoreactivity in human plasma. Gastroenterology 82: 438-444.

Walton, J. N. (1977) Brain's Diseases of the Nervous System, pp. 715-786, 878-987, Oxford University Press, Oxford. 